\title{
Correction to: Unpredicted occurrence of Aglae caerulea in the Pantanal wetland biome and its implications Apidae: Euglossini)
}

\author{
Evandson J. ANJos-SiLVA
}

Neotropical Bees and Wasps Laboratory, Department of Biology, University of Mato Grosso State, Av. Tancredo Neves 563, Cáceres, MT, Brazil

\section{Correction to: Apidologie https://doi.org/10.1007/s13592-019-00640-9}

Following publication of the original article, the author requested the publishing of a new map and reference as provided in this correction:

GBIF.org. (27th April 2019). GBIF Occurrence Download. https://doi.org/10.15468/dl.zsdf5x

Publisher's note Springer Nature remains neutral with regard to jurisdictional claims in published maps and institutional affiliations.

Corresponding author: E. Anjos-Silva, evandson@ unemat.br Manuscript editor: Klaus Hartfelder The online version of the original article can be found at https://doi.org/10.1007/s13592-019-00640-9 


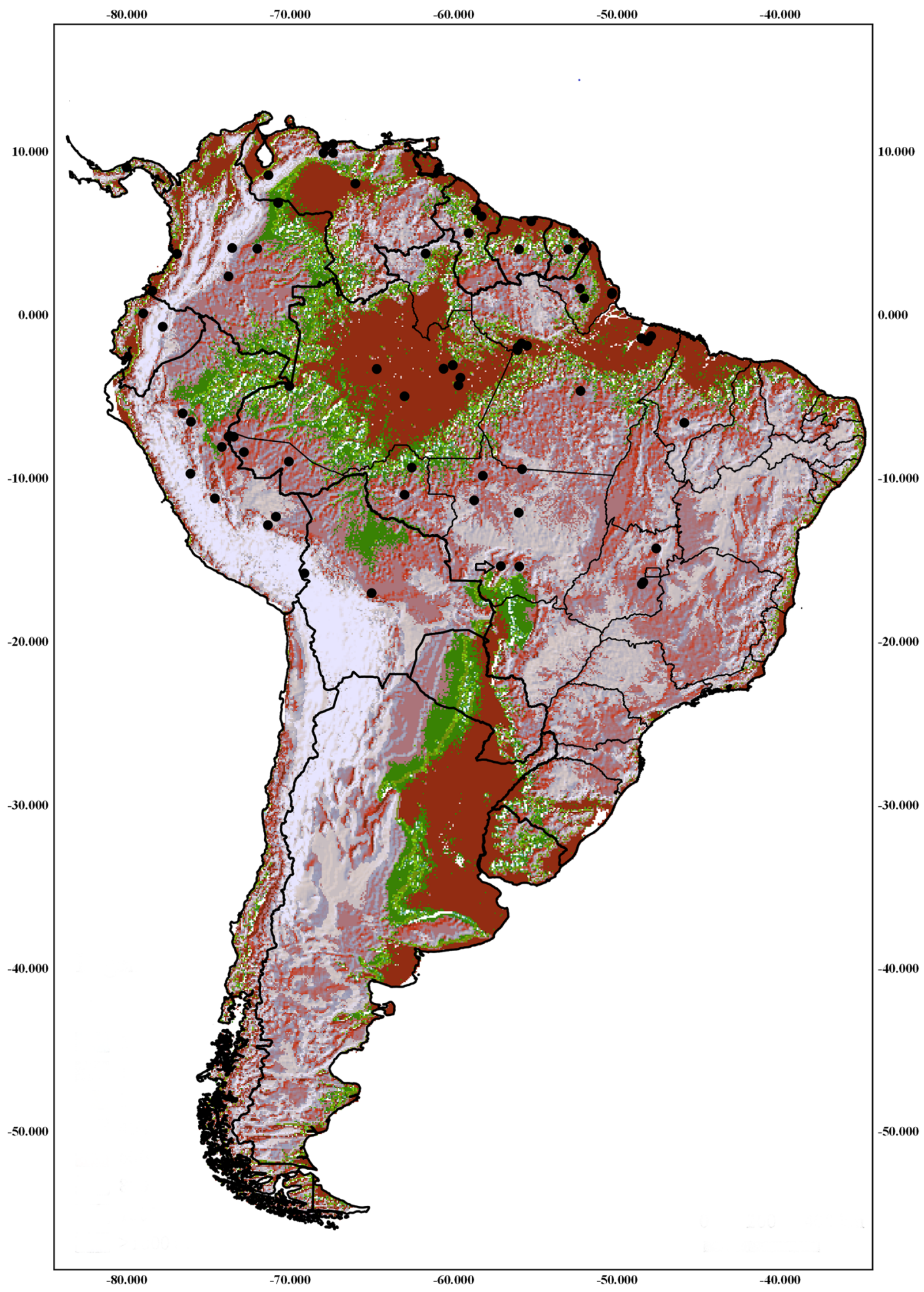

